\title{
Unexpected Findings in a Study of Visual Perception During the Naturalistic Near-Death Out-of-Body Experience
}

\author{
Janice Miner Holden, Ed.D. \\ University of North Texas
}

\begin{abstract}
A study (Holden, 1988) of visual perception during the naturalistic near-death out-of-body experience (nND OBE), that aspect of the NDE in which the experiencer seems to view normal physical surroundings from a vantage point outside the physical body, yielded some unexpected findings that contradicted or augmented previous research. The majority of respondents were able to estimate the duration of the $\mathrm{nND} O \mathrm{OBE}$; a sizable proportion reported delay of recall of the $\mathrm{nND} O \mathrm{OBE}$; and the vast majority reported receptivity to subsequent verification of $\mathrm{nND} O \mathrm{OBE}$ perceptions. Each of these findings is discussed relative to previous research and analyzed in light of the limitations of the current study. Implications for further research are discussed.
\end{abstract}

In order to elucidate some unresolved issues regarding near-death veridicality research in the hospital setting, I undertook a study (Holden, 1988) of visual perception during the naturalistic near-death out-of-body experience (nND OBE). The nND OBE, a frequent but not universal component of the near-death experience (NDE), occurs when the experiencer finds himself or herself outside of and usually in the vicinity of the physical body, viewing the physical surroundings. The study analyzed questionnaire responses from 63 near-death experi-

Dr. Holden is Assistant Professor of Counselor Education at the University of North Texas. Requests for reprints should be addressed to Dr. Holden at the Department of Counselor Education, College of Education, University of North Texas, P.O. Box 13857, Denton, TX 76203-3857. 
encers (NDErs) who had volunteered to join the subject pool of the International Association for Near-Death Studies (IANDS) and had indicated that their NDEs included an OBE. In addition to those findings previously reported, some unexpected findings emerged that were not relevant to the original intent of the study. These findings are the result of single-item responses; thus the reliability of the responses cannot be determined. But because the findings are of relevance to the understanding of, and future research into, the NDE, I present and discuss them in this paper.

\section{Duration of the nND OBE}

In the general OBE literature, which includes references to OBEs that occur both in and out of the context of an NDE, OBE duration is cited as typically ranging from a few seconds to 30 minutes (Blackmore, 1984, p. 231), with some spontaneous OBEs allegedly lasting up to two hours (Irwin, 1985, p. 137). Indeed, Harvey Irwin wrote that "generally there are few spontaneous OBEs that subjectively extend beyond an hour or two, and most of these cases were recorded many years ago" (p. 138).

Also according to Irwin, experiencers frequently report changes in the perception of time during the $\mathrm{OBE}$, that is, time being slower or not existing. In those few cases in which a comparison was possible, experiencers' subjective estimates of OBE duration were longer than objective referents would have suggested. He stipulated that "cues to the objective duration of an OBE, however, are rare" (1985, pp. 136-137).

Most near-death researchers have emphasized the predominant sense of timelessness, or meaninglessness of time, during the NDE (Moody, 1975, p. 47; Ring, 1980, p. 95ff). Perhaps because of this, estimates of NDE or $\mathrm{nND}$ OBE duration are missing in the near-death literature. Nevertheless, references to the passage of time, especially during the naturalistic ND OBE, do exist, as in the case of one subject who described that during his ND OBE, "the convulsions didn't last very long" (Sabom, 1982, p. 30). And experiencers usually describe in temporal sequence the events they seemingly observed during the nND OBE. Indeed, it follows that an estimate of duration during this component of the NDE might be possible because of the experiencer's references to physical events.

Because of the possible relevance of ND OBE duration to the visual perception study, a questionnaire item regarding estimated duration 
of the nND OBE was developed, taking into account the issues described above. Respondents were asked, "In 'earthly' time, about how long did your ND OBE last?" and were offered the option to write in their estimate in seconds or minutes, or to indicate, "Uncertain; I can't venture an estimate." Results for the item are shown in Figure 1.

First, $60 \%$ of these respondents were willing to estimate a duration for their nND OBEs. The fact that a majority could do so contradicts the general emphasis on timelessness or meaninglessness of time in the near-death literature. This finding is illustrated by a respondent whose $\mathrm{nND}$ OBE occurred in the aftermath of an auto racing accident. When asked whether he read or could have read during his experience, he indicated that reading material had been present, in the form of "my name, blood type, etc [sic] printed on my helmet." "But," he qualified, in the 2-3 seconds estimated duration of his nND OBE, "I did not have time to read [it]."

This finding may be interpreted as validation of the hypothesis that temporal estimation is more possible during this component of the NDE because of the reference to physical events. It may even be the case that NDErs who had a clearer sense of the passage of time during their NDEs are more likely to volunteer to become near-death research subjects. This is a matter for future research to resolve.

A second finding regarding estimation of the duration of one's $\mathrm{nND}$ OBE was that eight percent of the respondents took the initiative to write in durations of hours, days, and in one case, months. This finding extends substantially the duration of even the longest estimate cited in

Figure 1

Recalled duration of $\mathrm{nND}$ OBE

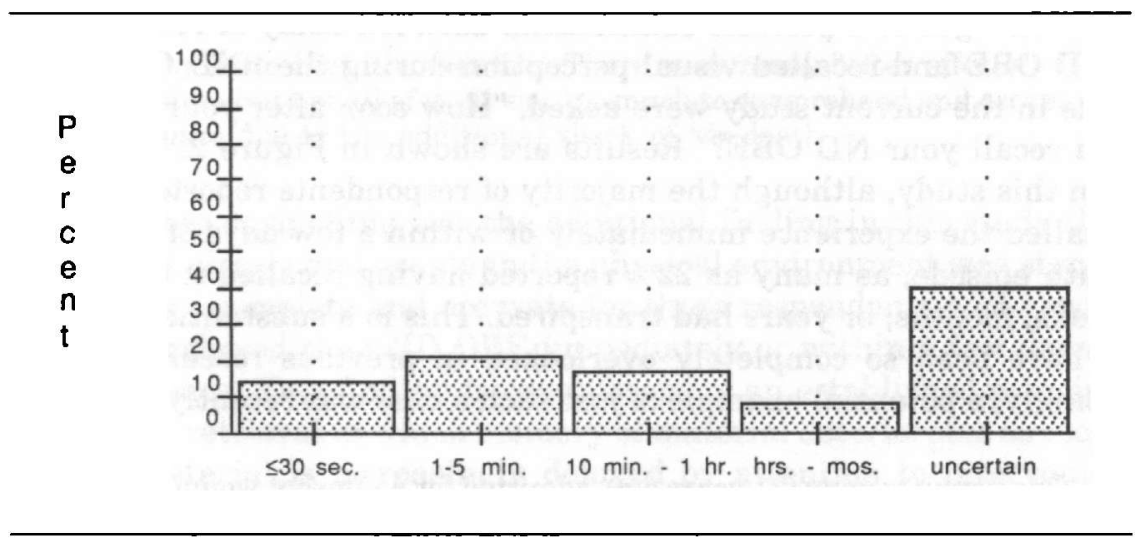


the OBE literature. It is an interesting question whether at least some of the $40 \%$ of respondents who reported uncertainty about their naturalistic ND OB duration might have estimated a duration of hours, days, or longer if such options had been provided; for at least some, the choice of "uncertain" may have resulted from being less assertive or conscientious about answering the question, rather than less certain when compared to the above-mentioned eight percent.

How objectively accurate these estimates were must currently remain a question, but this question presents another potential avenue of research. In any case, however the current findings are interpreted, future near-death researchers might, when it is deemed relevant to the research questions at hand, consider the possibility that an nND OBEr can provide an estimated duration of that component of the experience, and that the estimate may be a protracted period of time.

\section{Delay of Recall of the nND OBE}

Based on the absence in the literature of any reference to the contrary, it seems to have been assumed that recall of OBEs or NDEs is invariably immediate. Kenneth Ring (1984), however, described a rare occurrence involving knowledge of future events in the experiencer's personal life that was seemingly acquired during a long-past NDE. Some of these experiencers "will recall the knowledge only when the actual event happens. In this case . . it seems the event itself jars the memory of it, bringing back the NDE context in which the original perception was given" (p. 184). Whether such a delay of recall is ever associated with any other phase of the NDE, or possibly the entire NDE memory itself, has apparently not been addressed in the literature. In light of a possible relationship between delay of recall of the nND OBE and recalled visual perception during the nND OBE, subjects in the current study were asked, "How soon after your NDE did you recall your ND OBE?" Results are shown in Figure 2.

In this study, although the majority of respondents reported having recalled the experience immediately or within a few days of the neardeath episode, as many as $22 \%$ reported having recalled it only after weeks, months, or years had transpired. This is a substantial number to have been so completely overlooked in previous research. Interestingly, a potential example of just such a case was recently reported:

One young woman (21 years old), admitted for a gunshot wound to her chest and abdomen, remembered floating above her body in the emer- 
Figure 2

Delay of recall of $\mathrm{nND} O \mathrm{OBE}$

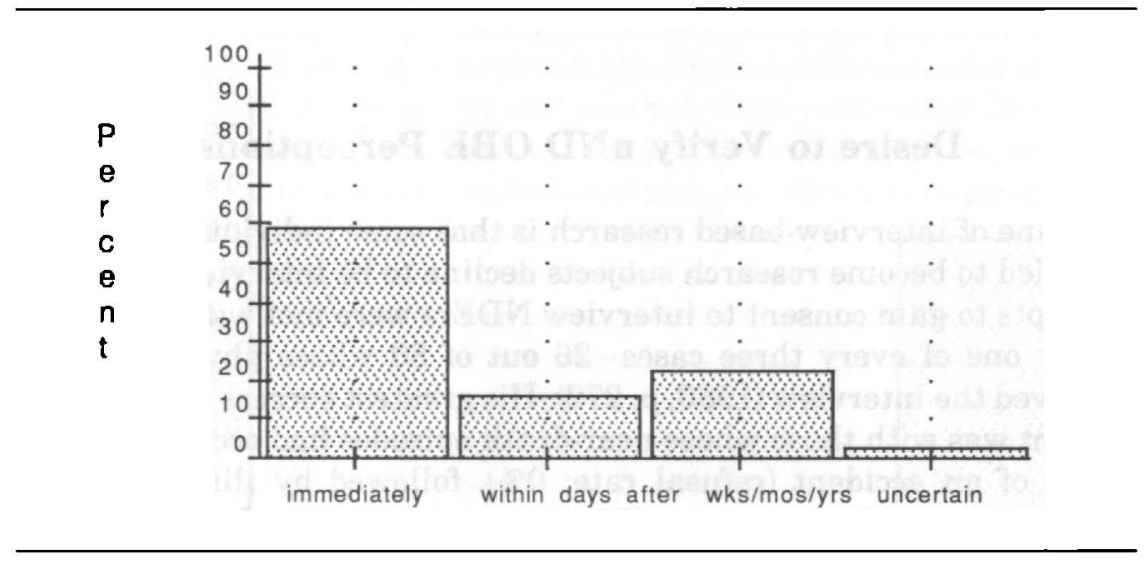

gency room watching hospital personnel cut off her garter belt. She remembered viewing the tops of people's heads with curiosity, and knew she felt calm. But she only remembered the "overhead shot" and the experience after being asked about it by the interviewer. It was so undramatic that she had not thought of it since it happened. (Olson, 1988 , p. 173)

However, the reader should not be left with the impression that uninteresting $\mathrm{nND}$ OBE content is the only reason for delay of recall of the experience. The husband of one respondent in this study had died as a result of the same accident during which the respondent had had her $\mathrm{NDE}$. In the course of explaining her delay in recalling her $\mathrm{nND}$ OBE, she described a classic example of suppression:

Little by little I let it come thru. There were many "after effects"-I blocked it-but not all of it-it was too much to comprehend and accept all at once due to the additional shock of his death.

Even more compelling was the additional finding in this study that memory of objects and events in the physical environment was significantly more complete and accurate for those respondents who reportedly remembered the $\mathrm{nND}$ OBE immediately or within a few days of its occurrence. This finding is reminiscent of an established principle of memory retrieval in which memory of material deteriorates as recall of that material is increasingly delayed by attention to intervening information (Fantino \& Reynolds, 1975, pp. 26-27). Future researchers 
of the NDE may be well advised to be aware that delay of recall of the nND OBE may be both a relatively frequent and a significant phenomenon.

\section{Desire to Verify nND OBE Perceptions}

A bane of interview-based research is that some individuals who are qualified to become research subjects decline to be interviewed. Ring's attempts to gain consent to interview NDErs were met with refusal in nearly one of every three cases -26 out of 80 whose physicians had approved the interview (1980, p. 272). His greatest success in obtaining consent was with those whose near-death episodes had occurred as the result of an accident (refusal rate: $0 \%$ ), followed by illness victims $(24 \%)$, and suicide-attempters $(56 \%)$, suggesting the role of "cause of ND episode" in willingness to be interviewed.

Of particular interest regarding hospital veridicality research was the extent to which the nND OBEr would be interested in objectively verifying what had seemingly been perceived during the experience. During a presentation of the proposed hospital veridicality research to a high school group, one student had challenged, "These people are dying, and you're messing with their minds!" An attempt to defend the study by citing nND OBErs' own interest in verification of perceptions proved to be poorly substantiated; although examples of such interest had appeared in the literature (Clark, 1984, p. 243; Grey, 1985, pp. 37-38; Ring, 1984, p. 43), this question had apparently not yet been systematically studied. Thus I decided to ask respondents, "Once you remembered your ND OBE, how would you have felt about someone approaching you with the opportunity to verify whether what you'd seen during your ND OBE matched what 'actually' happened?" The question was followed by five choices ranging from "very unreceptive" to "very receptive." Results are shown in Figure 3.

Clearly, the majority of these respondents recalled having been interested in verification, a finding that might be expected from a selfselected sample of nND OBErs who had, subsequent to their NDEs, volunteered to be research subjects. Less clear, perhaps, is why as many as $8 \%$ of this same sample reportedly recalled having felt unreceptive to verification. Further analysis yielded some relevant findings.

First, receptivity to verification upon remembering an NDE was not related to any aspect of naturalistic ND OB vision. In other words, those recalling receptivity to verification were no more or less likely to 


\section{Figure 3}

\section{Receptivity to verification}

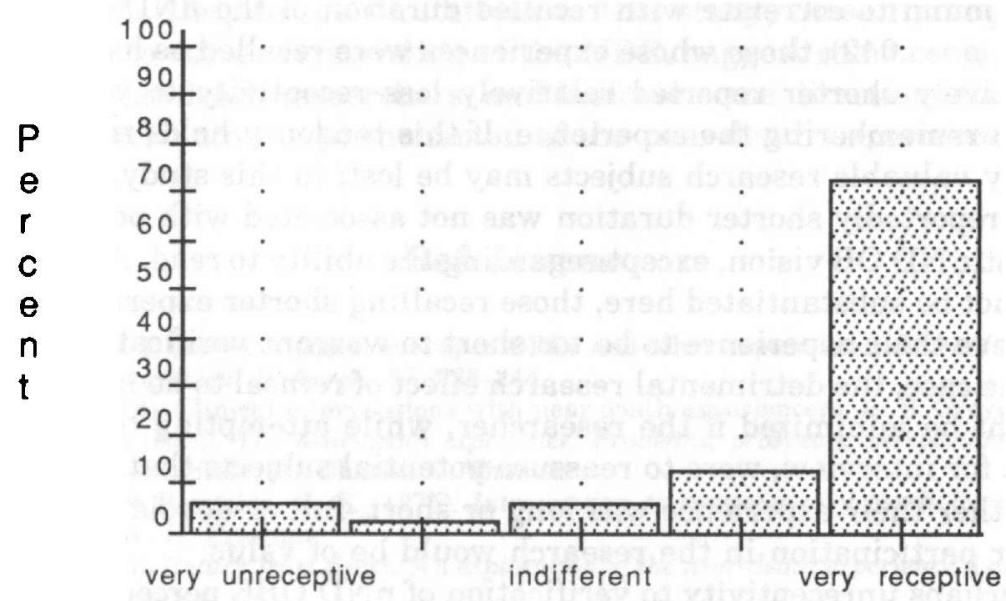

recall having seen clearly, seen a complete field of vision, perceived visual distortion, retained a complete and accurate memory of the physical environment, seen a complete and accurate color spectrum, been able to read, or attended to extraneous detail in the physical environment during the $\mathrm{nND} O \mathrm{OBE}$, than were those who recalled having felt unreceptive to verification. This seems to negate the possibility that naturalistic ND OBErs who refuse to become research subjects might do so because of having had a relatively less clear, or more distorted naturalistic ND OBE. However, the assumption cannot be rejected, because this study did not include a representative sample of subjects who, upon remembering their naturalistic ND OBEs, were unreceptive to verification. It does, however, suggest that factors other than the vividness or clarity of the NDE are responsible for a lack of receptivity.

Reported receptivity to verification upon remembering the NDE was found to correlate with time elapsed since the NDE $(r=.266 ; p=$ .036); those whose NDEs occurred more recently were reportedly more receptive to verification. This may be a reflection of a possible awareness on the part of respondents that NDE reports may have gained credibility in recent years. Thus if one's NDE occurred relatively long ago, one might have been reluctant to be interviewed due to a possibly greater skepticism and/or incredulity with which NDE reports were 
met at that time, compared to more recent times. Whatever the reason, this finding augurs well for the present-day near-death researcher.

Reported receptivity to verification upon remembering the NDE was also found to correlate with recalled duration of the $\mathrm{nND}$ OBE ( $\mathrm{r}=$ $.258 ; p=.042$ ); those whose experiences were recalled as having been relatively shorter reported relatively less receptivity to verification upon remembering the experience. If this tendency holds true, potentially valuable research subjects may be lost; in this study, for example, reportedly shorter duration was not associated with poorer naturalistic ND OB vision, except regarding the ability to read. Although it cannot be substantiated here, those recalling shorter experiences may believe their experience to be too short to warrant verification. If this is the case, the detrimental research effect of refusal to be interviewed might be minimized if the researcher, while attempting to gain consent for interview, were to reassure potential subjects that, no matter whether their experience was long or short, full or devoid of content, their participation in the research would be of value.

Perhaps unreceptivity to verification of $\mathrm{nND}$ OBE perceptions is, at least in part, much more straightforward than the above discussion would suggest. It is a pervasive finding that NDErs are insistent about the subjective reality of their experiences (Grey, 1985, p. 34; Jung, 1961, p. 295; Ring, 1980, pp. 82, 94; Sabom, 1982, p. 97). Consider one respondent from this study who, when asked about receptivity to verification, declared: "I don't understand-verify for whom? Myself? If myself, there was no need. I never doubted what I had experienced. It was as real and matter-of-fact as sitting here, writing this to you." In his case, the verification is clearly for us-those of us in the general population who have not experienced, but wonder about, the NDE and $O B E$; and the very few of us who have studied and are studying the mechanisms and meanings underlying these phenomena.

\section{Summary}

The findings reported herein should be interpreted with caution because of the self-selected nature of this sample, the relatively small number comprising this sample, and the fact that these findings were based on single-item responses, of which the reliability cannot be determined. With these limitations in mind, it was found in this study that: (1) the majority of respondents ventured an estimate of the duration of their nND OBEs, some of which purportedly lasted days, weeks, or months; (2) a sizable proportion of respondents reported a delay of 
recall of the $\mathrm{nND}$ OBE, which was found to be related to the quality of memory of the experience; and (3) the vast majority of respondents reported receptivity to verification of $\mathrm{nND} O B$ perceptions subsequent to the NDE. Despite the limitations of this study, these findings do contribute to our understanding of the NDE, suggest some considerations for near-death researchers, and indicate some directions for further research into the phenomenon of the near-death experience.

\section{References}

Blackmore, S. J. (1984). A postal survey of OBEs and other experiences. Journal of the Society for Psychical Research, 57, 225-244.

Clark, K. (1984). Clinical interventions with near-death experiencers. In B. Greyson \& C. P. Flynn (Eds.), The near-death experience: Problems, prospects, perspectives (pp. 242-255). Springfield, IL: Charles C. Thomas.

Fantino, E., \& Reynolds, G. S. (1975). Introduction to contemporary psychology. San Francisco: W. H. Freeman.

Grey, M. (1985). Return from death: An exploration of the near-death experience. London, England: Arkana.

Holden, J. M. (1988). Visual perception during the naturalistic near-death out-of-body experience. Journal of Near-Death Studies, 7, 107-120.

Irwin, H. J. (1985). Flight of mind: A psychological study of the out-of-body experience. Metuchen, NJ: Scarecrow Press.

Jung, C. G. (1961). Memories, dreams, reflections. New York: Random House.

Moody, R. A., Jr. (1975). Life after life. Covington, GA: Mockingbird.

Olson, M. (1988). The incidence of out-of-body experiences in hospitalized patients. Journal of Near-Death Studies, 6, 169-174.

Ring, K. (1980). Life at death. New York: Coward, McCann \& Geoghegan.

Ring, K. (1984). Heading toward omega. New York: William Morrow.

Sabom, M. B. (1982). Recollections of death: A medical investigation. New York: Simon \& Schuster. 